\title{
A EMPRESA NO ESTADO DEMOCRÁTICO DE DIREITO
}

\section{COMPANY IN THE DEMOCRATIC STATE OF LAW}

\author{
Sharon Cristine Ferreira de Souza"
}

\begin{abstract}
Resumo: Inicialmente se faz um breve apanhado histórico a fim de se analisar os modelos de Estado para se saber se realmente o chamado Estado Democrático de Direito é uma superveniência temporal desses paradigmas ou não. Em verdade, demonstra-se que a adstrição dos administrados, bem como do próprio Estado, ao ordenamento jurídico é uma construção surdida no Estado Liberal e que foi aperfeiçoada atualmente para que a democracia, fundada na observância do valor da dignidade humana, pudesse dar legitimidade ao estabelecimento de normas jurídicas. Nesta ótica, pode-se incluir a atuação empresarial, tanto sendo obrigada pela lei a cumprir os mandamentos legais em seu exercício, quanto sendo cobrada pela sociedade a exercer maior papel no auxílio ao Estado a alcançar o desenvolvimento sustentável. Por meio da responsabilidade social empresarial, as empresas vão ajudar o Estado nesse afã e ainda deverão observar as práticas democráticas que devem ser pressupostos e indicadores de seu agir socialmente responsável.
\end{abstract}

Palavras-chave: Estado Democrático de Direito. Empresas. Responsabilidade Social.

\begin{abstract}
Initially gives a brief historical overview in order to analyze the models of State to understand if really the called Democratic ruleof-law State is a temporal occurrence of these paradigms or not. In fact, demonstrates that the submission of the citizens, as well as the State itself, to the legal system is a construct that emerged in the the Liberal State that has been refined and now that democracy, founded on the observance of the value of human dignity, could give legitimacy the establishment of legal norms. In thisperspective, can be include business performance, both being obliged by law to fulfill the commandments legal in their exercise, as being charged by society to exercisemajor role in assisting the State to achieve sustainable development. Through CSR, companies will help the State in this effort and should still observe democratic practices to be indicators of their assumptions and acting socially responsible.
\end{abstract}

Key-words: Democratic State. Companies. Social Responsibility.

Doutoranda pelo Programa de Pós Graduação em Sociologia e Direito da Universidade Federal Fluminense. Email: sharoncris@gmail.com. 


\section{INTRODUÇÃO}

O Estado, entendido como um fenômeno que unifica os grupos de pessoas de uma nação sobre a estrutura formal da vida em comum, permitindo que, por meio desta estrutura, realizem-se os fins e conteúdos perseguidos, não exclui destes a influência recíproca entre Estado e sociedade - as trocas, as constantes respostas às demandas sociais ${ }^{1}$. Pode-se observar que a partir da década de 1970, o modelo de Estado intervencionista acaba abrindo espaço aos ideais neoliberais, os quais, não obstante tenham ganhado força e influenciado mais ou menos fortemente alguns Estados no mundo, não fizeram, ao menos no Brasil, com que se trocasse a concepção de solidariedade social constante no Texto Constitucional pela noção de competitividade. (CARINHATO, 2008, p. 45).

A solidariedade, bem como outros valores relevantes que, inclusive, caracterizavam o direcionamento de políticas públicas típicas do Estado Social, tornou-se objetivo cada vez mais forte e perseguido, principalmente após a observância de certos pressupostos neoliberais não solucionarem dados problemas sociais e econômicos, conforme inicialmente se idealizava.

Com isso, houve algumas mudanças, derivadas da chamada reforma do Estado - que pretendia a abstenção de certas obrigações sociais de fornecimento de bens e serviços para a sociedade -, mas por outro lado, se formava a figura de um Estado regulador, atribuindo parte de seus deveres à esfera particular (mercado e sociedade civil) e colocando-se como um fiscalizador da atividade privada com vistas à realização do bem comum.

A concessão de algumas atribuições ao mercado e à sociedade civil ainda traz problemas, pois as demandas sociais continuavam existindo e exigindo do Estado a intervenção e a positivação de valores relevantes e almejados pela sociedade, uma vez que, no caso do Estado Brasileiro, este tomou para si e de modo muito explícito a realização desses misteres, mas também - haja vista, repete-se, as influências neoliberais - a sociedade passa a reclamar do mercado, mediante a atuação empresarial, o papel que lhe cabe nesta situação

Neste contexto surge a questão da responsabilidade social das empresas, porém, outrossim, a necessidade de se entender seu funcionamento e sua concepção de modo a se coadunar com o Estado Democrático de Direito.

\footnotetext{
${ }^{1}$ Input (demanda) e output (resposta), consistentes nas trocas sistêmicas, em que a sociedade civil se dirige ao poder político com uma demanda, um valor ou necessidade a ser realizado, enquanto o Estado tem o dever de responder. O Estado deve atender aos reclamos da sociedade sob pena de perder a governabilidade e, em conseqüência disso, a legitimidade (BOBBIO, 2007, p. 36).
} 
Isto porque a empresa, ao ser cobrada pela sociedade, deve agir refletindo a observância dessas demandas sociais, mas ao mesmo tempo cumprindo o estabelecido no ordenamento jurídico; e, o Estado, por sua vez, tem o dever, como regulador e fiscalizador, trazer certas balizas para esse novo instituto que já existe de fato há algum tempo.

\section{ESTADO DEMOCRÁTICO DE DIREITO COMO PRESSUPOSTO DA ATUAÇÃO EMPRESARIAL SOCIALMENTE RESPONSÁVEL}

O Estado Democrático de Direito não é um modelo de Estado tal qual se estuda na ciência política, que tem como originário do Estado Moderno aquele Absolutista e, quando se faz a análise da evolução histórica, perpassa-se pelo Estado Liberal, Estado Social e Estado Neoliberal. Começa-se estudando o Estado de Direito com o advento do Estado Liberal, que em decorrência das Revoluções Francesa e Industrial, sedimentaram a máxima da hegemonia da liberdade, igualdade e fraternidade como o principal fundamento do modelo político a ser adotado.

Como sob a égide do Estado Absolutista, o soberano podia dispor a qualquer momento da vida, propriedade e liberdade de seus súditos, sob a justificativa da necessidade de um pulso forte para a manutenção da paz e harmonia social. Essa ingerência extremada e disponibilidade da vida, propriedade e liberdade de seus súditos teve seus reflexos no modelo econômico que o posterior Estado Liberal adotou. Sedimentou, assim, o pensamento do laissez faire ${ }^{2}$, criando a denominada doutrina do "Estado mínimo", onde este deveria existir apenas para aumentar a taxa média de lucro, fomentar a acumulação de capital ou, então, estruturar-se para atender aos reclamos das classes sociais mais organizadas.

Em nenhuma hipótese a figura do Estado poderia intervir na vida, propriedade e liberdade de seus administrados. Para tanto, a institucionalização do Estado Liberal pressupõe a criação do Poder Legislativo, cuja função seria a de estabelecer leis apreendidas e aplicadas a todos, inclusive, ao próprio Estado. Dispôs Locke (2006, p. 159) "seja quem for que detenha o poder legislativo,

\footnotetext{
2 "laissez faire, laissez passer, le monde va de lui même" ("deixar fazer, deixar passar, o mundo caminha por si mesmo") é uma expressão francesa, que denotava a exigência de um retraimento do Estado no âmbito social, surgida na segunda metade do século XVIII com o advento das revoluções burguesas, principalmente na Inglaterra, França e Estados Unidos da América do Norte, como base do pensamento liberal (VIEIRA, 2004, p. 196).

3 "O poder legislativo é o poder supremo em toda comunidade civil [...]" (LOCKE, 2006, p. 163).
} 
ou o poder supremo de uma comunidade civil, deve governar através de leis estabelecidas e permanentes, promulgadas e conhecidas do povo [...]”.

Ou seja, com o Estado Liberal surge o Estado de Direito, uma vez que o povo por meio do Poder Legislativo criaria leis e estas governariam o Estado e fariam a regência das relações sociais. Não mais um soberano poderia dispor, ao seu talante, da vida, propriedade, liberdade ou qualquer outra esfera das condutas humanas sem que para isso houvesse autorização legal. Inclusive, o próprio soberano, o próprio Estado estaria adstrito à lei.

Da perspectiva jurídica, o Estado de Direito, então, é aquele regido pelas leis. Porém, não basta que seja unicamente dirigido pelas leis, pois existe a possibilidade de estas serem criadas por uma única pessoa, por uma figura que faz as vezes de um ditador ou déspota. Será então ilegítima, perante os governados, a imposição de legislação que não foi devidamente acordada por determinada sociedade.

Portanto cabe dizer que a legitimidade para o estabelecimento de normas deve ter um caráter de consentimento universal, que só pode ocorrer mediante um processo democrático. A democracia moderna desde o seu nascimento assume a forma de democracia representativa, não obstante se entenda que ela deva ser aperfeiçoada para melhor funcionar nas sociedades modernas ou, até mesmo, ser substituída por outro tipo de democracia. Nesse sentido, toma-se o exemplo de Rousseau, contratualista que à sua época defendia a direta como melhor forma de democracia.

Para evitar que vigesse a lei dos mais fortes, a escravidão, o jugo dos mais poderosos ou qualquer outra situação caótica em decorrência da desigualdade surdida com a propriedade, resta aos indivíduos convencionarem como se dará a autoridade legítima numa sociedade. "Visto que homem algum tem autoridade natural sobre seus semelhantes e que a força não produz nenhum direito, só restam as convenções como base de toda a autoridade legítima existente entre os homens" (ROUSSEAU, 1999b, p. 61).

Com efeito, mediante um pacto social, uma convenção na qual cada homem, permanecendo tão livre quanto o era no estado de natureza, "põe em comum sua pessoa e seu poder sob a direção suprema da vontade geral”, para fazer parte desse corpo político e submetido às leis promulgadas pelos próprios membros dessa república (ROUSSEAU, 1999b, p. 71).

O pacto forma um ente público ${ }^{4}$ que reúne a vontade geral, que é a vontade

\footnotetext{
4 "Essa pessoa pública, que se forma, desse modo, pela união de todas as outras, tomava antigamente o nome de cidade e, hoje, o de república ou de corpo político, o qual
} 
coletiva visando ao bem comum e a felicidade de todos, a qual, por intermédio do soberano, pretende tutelar a liberdade e reger a sociedade de forma que não haja imposição de força, isto é, a fim de que se dê de maneira legítima.

Todos os indivíduos, pois, exerceriam um duplo papel, como cidadãos, uma vez membros do soberano, e como súditos, quando submetidos às leis estatais. Por meio do pacto social, o homem perde a liberdade natural para ingressar na sociedade civil com a liberdade civil e a propriedade de tudo o que possui, devendo submeter-se à vontade geral determinada pelo soberano, limitada somente pelas convenções gerais estabelecidas por ele.

Como membro do soberano, cada pessoa vai comprometer-se na medida em que se compromete consigo mesma e perante todos, razão pela qual as leis ${ }^{5}$ são tidas como a instituição da vontade geral e, por conseguinte, sua expressão pode ser feita apenas mediante participação popular. O Governo deveria ser confiado ao povo ou a maior parte dele. A democracia representativa era repudiada sob o entendimento de não expressar efetivamente a vontade geral e não representar os principais objetivos do sistema legislativo, quais sejam: a igualdade e a liberdade. (ROUSSEAU, 1999b, 127-147).

Desta forma, entende-se que não basta somente a vigência de um Estado de Direito, mas sim um Estado de Direito cujas normas estabelecidas foram discutidas e criadas, para serem impostas, de maneira democrática, isto é com o povo decidindo quais são as leis às quais desejam estar adstritos, dito de outra forma, quais são as normas mais adequadas e corretas que podem instituir o Estado que se deseja implementar.

Com esta ideia em mente, se se pegar o Estado Brasileiro poder-se-á analisar como se dá o Estado Democrático de Direito do Brasileiro e de que modo funciona a questão da responsabilidade social empresarial, isto é, como o Estado Democrático determina, de certa forma, a atuação das empresas no Brasil. Para tanto, há necessidade de utilizar como base o Texto Constitucional a começar pelo seu Preâmbulo:

Nós, representantes do povo brasileiro, reunidos em Assembléia Nacional Constituinte para instituir um Estado Democrático, destinado a assegurar o

é chamado por seus membros de Estado quando passivo, soberano quando ativo, e potência quando comparado a seus semelhantes. Quanto aos associados, recebem eles, coletivamente, o nome de povo e se chamam, em particular, cidadãos, enquanto partícipes da autoridade soberana, e súditos enquanto submetidos às leis do Estado" (ROUSSEAU, 1999a, p. 71).

${ }^{5} \mathrm{O}$ sujeito "pode ser livre e estar sujeito às leis, desde que estas não passam de registros de nossas vontades" (ROUSSEAU, 1999b, 107). 
exercício dos direitos sociais e individuais, a liberdade, a segurança, o bemestar, o desenvolvimento, a igualdade e a justiça como valores supremos de uma sociedade fraterna, pluralista e sem preconceitos, fundada na harmonia social e comprometida, na ordem interna e internacional, com a solução pacífica das controvérsias, promulgamos, sob a proteção de Deus, a seguinte CONSTITUIÇÃO DA REPÚBLICA FEDERATIVA DO BRASIL. (Grifo nosso).

Com a leitura do Preâmbulo Constitucional acima colocado pode-se perceber que houve a instituição de um Estado Democrático o qual, por meio de normas constitucionais e também de outros comandos normativos presentes no ordenamento jurídico pátrio, foi positivado para dar legitimidade à forma de seleção e execução dos direitos que o Estado Brasileiro persegue.

Sendo assim, o "exercício dos direitos sociais e individuais, a liberdade, a segurança, o bem-estar, o desenvolvimento, a igualdade e a justiça” são valores que deverão ser observados e realizados democraticamente por meio de normas, bem como as características do Estado Brasileiro que devem guiar, igualmente, a feitura de tais normas: "uma sociedade fraterna, pluralista e sem preconceitos, fundada na harmonia social e comprometida, na ordem interna e internacional, com a solução pacífica das controvérsias”.

Com isso a Constituição da República Federativa do Brasil de 1988 abre caminho para determinar as políticas de Estado que o povo brasileiro escolheu como seus objetivos e fundamentos:

Art. 1ำ A República Federativa do Brasil, formada pela união indissolúvel dos Estados e Municípios e do Distrito Federal, constitui-se em Estado Democrático de Direito e tem como fundamentos: I - a soberania; II - a cidadania; III - a dignidade da pessoa humana; IV - os valores sociais do trabalho e da livre iniciativa; $\mathrm{V}$ - o pluralismo político. [...]

Art. $3^{\circ}$ Constituem objetivos fundamentais da República Federativa do Brasil: I - construir uma sociedade livre, justa e solidária; II - garantir o desenvolvimento nacional; III - erradicar a pobreza e a marginalização e reduzir as desigualdades sociais e regionais; IV - promover o bem de todos, sem preconceitos de origem, raça, sexo, cor, idade e quaisquer outras formas de discriminação.

Art. 4 A República Federativa do Brasil rege-se nas suas relações internacionais pelos seguintes princípios: I - independência nacional; II - prevalência dos direitos humanos; III - autodeterminação dos povos; IV - não-intervenção; V - igualdade entre os Estados; VI - defesa da paz; VII - solução pacífica dos conflitos; VIII - repúdio ao terrorismo e ao racismo; IX - cooperação entre os povos para o progresso da humanidade; X - concessão de asilo político.

Nesses dois dispositivos constitucionais supracitados quis destacar-se alguns detalhes, como por exemplo, o Art. 1ํㅡㄹ inciso III que traz como fundamento 
principal do Estado Brasileiro a dignidade da pessoa humana - importância esta reforçada pelo dispositivo Art. 4을 inciso II o qual trata da prevalência dos direitos humanos. Por certo o artigo elenca mais alguns valores essenciais que devem fundar o Estado e não coloca, explicitamente, a dignidade humana como o principal valor. Todavia, não há como negar a hegemonia deste princípio, que orienta principalmente toda interpretação doutrinária em torno do Direito e, porque não dizer, que deve determinar todo o agir humano em suas relações intersubjetivas.

[...] o homem, e em geral todo ser racional, existe como fim em si, não apenas como meio, do qual esta ou aquela vontade possa dispor a seu talento; mas, em todos os seus atos, tanto nos que se referem a ele próprio, como nos que se referem a outros seres racionais, ele deve sempre ser considerado ao mesmo tempo como fim. ${ }^{6}$ (KANT, p. 28).

Destarte, tem-se o termo dignidade humana como o reconhecimento de um valor. O ser humano é um fim em si mesmo e, como tal, tem manifestações de racionalidade, liberdade e finalidade em si. Essa auto-realização exige o reconhecimento dos outros indivíduos, bem como o respeito, liberdade de ação e a não utilização da pessoa como instrumento para outros fins.

Pós guerras mundiais o princípio da dignidade da humana foi revitalizado e inserido não apenas na Declaração Universal dos Direitos Humanos ${ }^{7}$ (1948),

${ }^{6}$ Kant defendia o imperativo categórico. Era a racionalidade que separava o homem dos seres irracionais, chamados de coisa. Kant entendia que as pessoas tinham dignidade e, portanto, não poderiam ser coisificadas. Todo ser humano, conforme este autor, possuía a dignidade como valor inerente, uma vez que os serem humanos eram entendidos como entes morais.

${ }^{7}$ Documento em cujo preâmbulo determina: "Considerando que o reconhecimento da dignidade inerente a todos os membros da família humana e de seus direitos iguais e inalienáveis é o fundamento da liberdade, da justiça e da paz no mundo; considerando que o desprezo e o desrespeito pelos direitos humanos resultaram em atos bárbaros que ultrajaram a consciência da Humanidade e que o advento de um mundo em que os todos gozem de liberdade de palavra, de crença e da liberdade de viverem a salvo do temor e da necessidade foi proclamado como a mais alta aspiração do ser humano comum; considerando ser essencial que os direitos humanos sejam protegidos pelo império da lei, para que o ser humano não seja compelido, como último recurso, à rebelião contra a tirania e a opressão; considerando ser essencial promover o desenvolvimento de relações amistosas entre as nações; considerando que os povos das Nações Unidas reafirmaram, na Carta da ONU, sua fé nos direitos humanos fundamentais, na dignidade e no valor do ser humano e na igualdade de direitos entre homens e mulheres, e que decidiram promover o progresso social e melhores condições de vida em uma liberdade mais ampla, considerando que os Estados-Membros se comprometeram a promover, em cooperação com as Nações Unidas, o respeito universal aos direitos e liberdades humanas fundamentais e a 
mas também nos textos constitucionais de vários Estados ao redor do mundo, a fim de se manterem alguns direitos fundamentais essenciais à manutenção da vida em sociedade (BERNARDO, 2006, p. 234; EMERIQUE, 2006, p. 383).

Outro importante objetivo, constante no Art. $3^{\circ}$ da Constituição Federal será determinante para se analisar como se dá a ligação entre Estado e empresas, estas em sua atuação no âmbito da responsabilidade social. É este o mister de garantir o desenvolvimento nacional. Pode-se observar que nos demais dispositivos constitucionais que trazem normas e princípios, todos buscam realizar valores que efetivamente garantam que o Estado Brasileiro esteja rumando para o caminho do desenvolvimento nacional, aqui trazido como sinônimo de desenvolvimento sócio-econômico, entendido como a execução dos valores sociais, econômicos, políticos e culturais por meio de normas jurídicas a fim de se alcançar um patamar de pleno vivenciamento da qualidade de vida, a observância da dignidade humana e a realização da justiça social.

Para tanto, observar-se-á que nos artigos seguintes a Constituição Federal trouxe uma série de direitos, frutos dos modelos históricos trazidos pelos Estados Liberal (Direitos e Garantias Individuais), Social (Direitos Sociais) e direitos entendidos como de $3^{\underline{a}}$ geração, como o direito ao meio ambiente ecologicamente equilibrado.

TÍTULO II - Dos Direitos e Garantias Fundamentais; CAPÍTULO I DOS DIREITOS E DEVERES INDIVIDUAIS E COLETIVOS

Art. 5o Todos são iguais perante a lei, sem distinção de qualquer natureza, garantindo-se aos brasileiros e aos estrangeiros residentes no País a inviolabilidade do direito à vida, à liberdade, à igualdade, à segurança e à propriedade, nos termos seguintes:

CAPÍTULO II - DOS DIREITOS SOCIAIS

Art. $6^{\circ}$ São direitos sociais a educação, a saúde, a alimentação, o trabalho, a moradia, o lazer, a segurança, a previdência social, a proteção à maternidade e à infância, a assistência aos desamparados, na forma desta Constituição.

TÍTULO VIII - Da Ordem Social; CAPÍTULO I - DISPOSIÇÃO GERAL Art. 193. A ordem social tem como base o primado do trabalho, e como objetivo o bem-estar e a justiça sociais.

Seção II - DA CULTURA

Art. 215. O Estado garantirá a todos o pleno exercício dos direitos culturais e acesso às fontes da cultura nacional, e apoiará e incentivará a valorização e a difusão das manifestações culturais.

observância desses direitos e liberdades, considerando que uma compreensão comum desses direitos e liberdades é da mais alta importância para o pleno cumprimento desse compromisso.” (Grifo nosso). 
Seção III - DO DESPORTO

Art. 217. É dever do Estado fomentar práticas desportivas formais e nãoformais, como direito de cada um, observados:

CAPÍTULO VI - DO MEIO AMBIENTE

Art. 225. Todos têm direito ao meio ambiente ecologicamente equilibrado, bem de uso comum do povo e essencial à sadia qualidade de vida, impondo-se ao Poder Público e à coletividade o dever de defendê-lo e preservá- lo para as presentes e futuras gerações.

CAPÍTULO VII - DA FAMÍLIA, DA CRIANÇA, DO ADOLESCENTE, O JOVEM E DO IDOSO

Art. 226. A família, base da sociedade, tem especial proteção do Estado.

Finalmente, por último colocam-se os dispositivos constitucionais que falam como a atividade econômica deverá ser desenvolvida no Brasil:

TÍTULO VII - Da Ordem Econômica e Financeira; CAPÍTULO I - DOS PRINCÍPIOS GERAIS DA ATIVIDADE ECONÔMICA

Art. 170. A ordem econômica, fundada na valorização do trabalho humano e na livre iniciativa, tem por fim assegurar a todos existência digna, conforme os ditames da justiça social, observados os seguintes princípios: I - soberania nacional; II - propriedade privada; III - função social da propriedade; IV - livre concorrência; V - defesa do consumidor; VI - defesa do meio ambiente, inclusive mediante tratamento diferenciado conforme o impacto ambiental dos produtos e serviços e de seus processos de elaboração e prestação; VII redução das desigualdades regionais e sociais; VIII - busca do pleno emprego; IX - tratamento favorecido para as empresas de pequeno porte constituídas sob as leis brasileiras e que tenham sua sede e administração no País. (grifo nosso)

Não obstante o Estado tenha suas atribuições constantes dos dispositivos acima (dentre outros), como o de promover o desenvolvimento sócioeconômico mediante a implementação das políticas de Estado traçadas no Texto Constitucional, ainda assim sob a égide do Estado Democrático de Direito Brasileiro o mercado não pode agir como melhor lhe aprouver. Devem as atividades econômicas obedecer, em sua atuação, os princípios trazidos no Art. 170. Observa-se, mais uma vez, a dignidade humana balizando as condutas humanas mediante o dever de haver a valorização do trabalho humano e a asseguração de existência digna conforme os ditames de justiça social.

Pode-se dizer que a empresa, no Brasil, não pode atuar sem obedecer a função social de sua atividade. E a função social da atividade econômica é agir sim em busca do lucro - o que caracteriza o mercado -, porém, obedecendo às normas pátrias (normas fiscais, trabalhistas, econômicas etc.) mediante a observância da soberania nacional, a garantia da propriedade privada, mas desde que esta cumpra sua função social, a defesa da livre concorrência, respeitar o direito do consumidor, agir de forma ecologicamente sustentável, a fim de que não 
haja a degradação do meio ambiente, atuar de forma a buscar a redução das desigualdades regionais e sociais, pretender o pleno emprego e, ainda, quando for micro ou pequena empresa, receber tratamento favorecido por parte da legislação brasileira.

Consoante se observou acima, esse rol trazido pelo Art. 170 da Constituição Federal dispõe a respeito da função social da empresa. Porém, a partir de meados da década de 1970, a "simples" função social da empresa não é mais o suficiente para atender aos anseios sociais. Isto porque a partir da segunda metade do século XX começa paulatinamente nos Estados Unidos, Canadá e na Europa - mais especificamente no Reino Unido - a surgir a concepção de ética dos negócios, baseada na credibilidade que a empresa deveria ter perante a sociedade. (CORTINA, 2001, p. 268; PEREIRA, 2006, p. 227) A confiança converte-se em valor empresarial e as empresas são levadas a pensar em resultados mediatos, entendo, outrossim, que suas ações deveriam ser pensadas tendo em vista o futuro e suas decisões passíveis de responsabilização ${ }^{8}$.

Em razão de escândalos como o acontecido nos anos 70 com o caso Watergate e, posteriormente, com o renascimento dessa discussão ética em 2002 com os emblemáticos casos Enron (CARVALHO, 2004) e WorldCom (WHARTON, 2003), a importância da ética empresarial e do papel das empresas começaram a ser debatidos, bem como a se levantar questionamentos como até que ponto pode se sustentar uma atividade econômica sem a observância de valores éticos.

Concomitantemente a essa questão ética que pôs em xeque a confiança das empresas, estavam se difundindo os ideais neoliberais que propunham um reducionismo estatal para o fomento de um Estado regulatório o qual deveria se adstringir a regulamentar e fiscalizar determinadas atividades, que poderiam ser realizadas pelo setor privado e não necessariamente colocadas como deveres e atribuições estatais.

Esse cenário foi propício ao surgimento da chamada responsabilidade social das empresas. Isso porque em sua atividade deveria existir a transparência e ética que a sociedade desejava ver nas empresas, evitando novos "casos Watergate" e com isso possibilitando que, paulatinamente, as empresas conseguissem novamente a confiança das pessoas. E não apenas isso, não apenas uma ética empresarial tornou-se determinante, mas também um agir que fosse além das

8 "Haciendo esto contribuirían a la protección del medio ambiente y a mejorar la sociedad mediante la interacción con aquellos con los que sus actividades tienen repercusión. [...] Es el deber de las empresas de contribuir al desarrollo sostenible trabajando con los empleados, sus familias, la comunidad local y la sociedad en la mejora de su calidad de vida”. (PEREIRA, 2006, p. 227). 
obrigações legais empresariais, um agir que fosse além da função social da empresa, a qual nada mais é do que a empresa agindo em conformidade com o prescrito em lei.

Somente atuar segundo a legislação não seria mais o suficiente, pois as empresas deveriam dar "em troca" para a sociedade muito mais do que "tomam" com sua atividade. Por conta das externalidades negativas e positivas que resultam da atividade econômica, a sociedade se viu no direito de cobrar um algo mais da atuação da empresa. E esse atuar que extrapola os limites estabelecidos em lei (função social) deve ser entendido como responsabilidade social.

Por essa razão, acima se frisou o Art. $3^{\circ}$, inciso II da Constituição Federal, o qual dispõe ser um dos objetivos da República Federativa Brasileira a garantia do desenvolvimento nacional. Ora, uma vez que o Estado Brasileiro possui todas as políticas de Estado acima observadas como de adimplemento obrigatório - sob pena de perder a legitimidade de sua institucionalização - e, ao mesmo tempo, sofre pressão externa para reduzir suas atribuições consoante determinam os ideais neoliberais, alguma instituição ou entidade deve auxiliar o Estado a conseguir alcançar o desenvolvimento sócio-econômico - o alcance do patamar de pleno vivenciamento da qualidade de vida, a observância da dignidade humana e a realização da justiça social. Essa entidade jurídica é a empresa, que vai suprir o vácuo deixado pelo Estado no cumprimento de suas atribuições e ajudá-lo a alcançar o desenvolvimento sócio-econômico por intermédio da responsabilidade social.

E com a responsabilidade social a atividade empresarial poderá agir com o enfoque em três âmbitos que integram as possibilidades do atuar socialmente responsável: i) sociedade; ii) âmbito externo; e iii) âmbito interno:

i) com relação à toda a sociedade a empresa mostra-se como responsável quando utiliza parte de seus recursos em projetos, em ajuda financeira a organizações não-governamentais, na criação de institutos ou fundações para fornecer serviços e bens públicos ou para defender causas sociais, ecológicas, educacionais e quaisquer outras atividades envolvendo os cidadãos;

ii) em âmbito externo, ou seja, da empresa com seus concorrentes, com as demais empresas, com seus consumidores, com o público alvo de sua atuação, será considerada socialmente responsável a empresa ao relacionarse de maneira correta com seus fornecedores, com as demais empresas que atuam na mesma atividade (concorrentes) e com os consumidores. Mas esse agir não é simplesmente guiado pelos princípios da livre concorrência, livre iniciativa e respeito aos consumidores conforme a 
função social determina. É uma atuação que vai além, com a criação de conselhos, projetos e ajuda a organizações que miram a conscientização do consumidor, por exemplo;

iii) e, finalmente, em âmbito interno, ou seja, da empresa com seus funcionários, gerentes, acionistas, enfim, no campo intra-empresa, a social responsabilidade faz com que se prime pelo investimento em educação, cursos profissionalizantes e quaisquer outros tipos de atividades que primem por explorar e incentivar ao máximo a capacidade, criatividade e habilidade de seus funcionários.

São exemplos os trazidos acima de como pode uma atividade empresarial ser socialmente responsável. Um Estado Democrático de Direito, cujo ordenamento jurídico é encabeçado por um Texto Constitucional portador de políticas de Estado em prol do desenvolvimento sócio-econômico, tem como obrigação o seu adimplemento. E o papel das empresas é o de agir harmoniosamente com essas normas e buscar auxiliar o Estado, mediante a responsabilidade social, a alcançar o desenvolvimento nacional.

A relação entre Estado Democrático de Direito, cujos pressupostos foram trazidos na introdução deste trabalho, e empresa não residem apenas na adstrição às normas jurídicas pátrias, mas também à implementação, em toda sua atuação, do processo democrático, que consistirá no diálogo, na participação e acordo de todos nas decisões a serem tomadas.

\section{A DEMOCRACIA NA EMPRESA: INSTRUMENTO E INTERFACE DA RESPONSABILIDADE SOCIAL}

Conforme analisado anteriormente, o Estado Democrático de Direito tem como pressuposto a realização dos valores elencados em seu texto (instrumento) de instituição (no caso do Brasil, a Constituição Federal), traçados sob a forma de Princípios, direitos e garantias. Porém, possui também como condição de sua existência que o estabelecimento desses objetivos e fundamentos seja realizado de maneira democrática, a fim de conceder legitimidade às escolhas e execução de tais valores.

Já foi observado, outrossim, que a forma pela qual empresa pode atuar segundo os ditames destes parâmetros estabelecidos no Estado Democrático de Direito Brasileiro é a da atuação consoante à função social e responsabilidade social. A função social é o mínimo juridicamente estabelecido para que a empresa cumpra (Art. 170, CF), com o intuito de se encontrar legalmente possibilitada de exercer sua atividade. 
E a responsabilidade social pode ser considerada como o meio mais apto à observância e alcance do desenvolvimento sócio-econômico. Caracterizada pela necessidade de uma mudança no modo de gestão empresarial direcionado ao exercício de ações e condutas além do estabelecido pelo Direito como deveres legais, não se optou em analisar especificamente cada um dos campos de atuação empresarial que engloba a questão da responsabilidade social - seara externa, sociedade e seara interna -, mas sim a relação direta que guarda a responsabilidade social com a questão da democracia.

A responsabilidade social tem em seu âmago a ideia de diálogo, consenso, discussão entre todas as partes interessadas na atuação empresarial. Por essa razão, trar-se-á à baila alguns documentos e institutos importantes na seara da social responsabilidade com o escopo de demonstrar o quão forte é a concepção de democracia - diálogo, debate e consenso entre as partes interessadas a fim de dar legitimidade às escolhas.

Primeiramente se deve fazer menção ao Instituto Ethos de Empresas e Responsabilidade Social", uma organização sem fins lucrativos "com o propósito de auxiliar as empresas a assimilar o conceito de responsabilidade social empresarial e incorporá-lo ao dia-a-dia de sua gestão, num processo contínuo de avaliação e aperfeiçoamento" (ETHOS), o qual define responsabilidade social como

a forma de gestão que se define pela relação ética e transparente da empresa com todos os públicos com os quais ela se relaciona e pelo estabelecimento de metas empresariais que impulsionem o desenvolvimento sustentável da sociedade, preservando recursos ambientais e culturais para as gerações futuras, respeitando a diversidade e promovendo a redução das desigualdades sociais. (Grifo nosso).

Frisa-se com o destaque, então, que o escopo da gestão socialmente responsável é o desenvolvimento sócio-econômico e, baseado nisso, esse instituto se propôs

\footnotetext{
9 "O Instituto Ethos de Empresas e Responsabilidade Social é uma organização sem fins lucrativos, caracterizada como Oscip (organização da sociedade civil de interesse público). Sua missão é mobilizar, sensibilizar e ajudar as empresas a gerir seus negócios de forma socialmente responsável, tornando-as parceiras na construção de uma sociedade justa e sustentável. Criado em 1998 por um grupo de empresários e executivos oriundos da iniciativa privada, o Instituto Ethos é um polo de organização de conhecimento, troca de experiências e desenvolvimento de ferramentas para auxiliar as empresas a analisar suas práticas de gestão e aprofundar seu compromisso com a responsabilidade social e o desenvolvimento sustentável. É também uma referência internacional nesses assuntos, desenvolvendo projetos em parceria com diversas entidades no mundo todo." http://www.ethos.org.br/
} 
a ajudar as empresas a implementarem a gestão responsável. Também se coloca essa organização como um expoente sobre o assunto, pois além de propor o estudo e discussão sobre o tema, se apresenta como pioneira e um referencial seguido no Brasil no âmbito empresarial.

Em seu afã de dar auxílio às empresas, o Instituto Ethos criou alguns indicadores, tanto um geral, como um - desenvolvido em parceria com o SEBRAE $^{10}$ - dirigido às micro e pequenas empresas, cujo objetivo é fazer com que as empresas saibam como incluir em sua gestão diretrizes e parâmetros necessários a uma atuação direcionada ao desenvolvimento sócio-econômico. Justamente isto é colocado como nota explicativa dos indicadores ${ }^{11}$ :

Os Indicadores Ethos de Responsabilidade Social Empresarial são uma ferramenta que tem auxiliado fortemente as empresas no sentido de permitir que incorporem em sua gestão os conceitos e compromissos que assumem em favor do desenvolvimento sustentável. (ETHOS, 2009, p. 2, grifo nosso).

Os indicadores possuem, ainda, outros objetivos além de servir como instrumento a ser levado em conta pelas empresas quando da realização de mudança na gestão visando ao caminho da social responsabilidade, como por exemplo:

Integrá-los com as principais ferramentas de gestão, metodologias e iniciativas em RSE e sustentabilidade desenvolvidas por outras organizações, dando especial ênfase à Norma ISO 26000, a ser lançada em dezembro de 2010; (ETHOS, 2009, p. 3, grifo nosso).

Atualizá-los às mais recentes discussões em responsabilidade social (por exemplo, mudanças climáticas, gestão da cadeia de valor, produtos e serviços sustentáveis, desenvolvimento territorial sustentável, etc), no sentido de sugerir práticas de gestão que tratem dessas questões. (ETHOS, 2009, p. 3, grifo nosso).

O primeiro destaque foi colocado para fazer alusão à ISO 26000, que será posteriormente abordada neste trabalho. E o segundo realce foi colocado justamente para, de início e já na proposta dos indicadores, demonstrar o papel relevante que possui o diálogo, as discussões sobre responsabilidade, que são extremamente necessárias para se aferir conceitos, concepções sobre o tema, além de fazer com que as partes interessadas cheguem a um consenso a respeito desses conceitos mesmos.

Nesse mesmo prólogo dos indicadores, frisam-se questões concernentes à ideia de responsabilidade social, mas sempre com os valores inerentes ao

\footnotetext{
${ }^{10}$ Serviço Brasileiro de Apoio às Micro e Pequenas empresas.

${ }^{11}$ http://www.ethos.org.br/docs/conceitos praticas/indicadores/download/
} 
desenvolvimento sustentável atrelados à noção de diálogo, engajamento e participação de todos os stakeholders. Coloca-se: "A responsabilidade social empresarial (RSE) implica práticas de diálogo e engajamento da empresa com todos os públicos ligados a ela, a partir de um relacionamento ético e transparente." (ETHOS, 2009, p. 6).

Especificamente destacados dentre os quarenta (40) indicadores, os quais são aferidos por intermédio das respostas a serem dadas nos questionários colocados num longo formulário, alguns pontos ligados à questão da democracia, ou seja, diálogo, interação entre as partes interessadas, são destacados para demonstrar que esse processo democrático além de um reflexo de uma atuação socialmente responsável, é um pressuposto deste instituto.

Indicador 1 - Compromissos Éticos (Com relação à adoção e abrangência de valores e princípios éticos):

Estágio 4: Além disso, o código de conduta da organização prevê a participação das principais partes interessadas em sua revisão e é submetido a controle e auditoria periódicos. A responsabilidade dessas ações está formalmente a cargo de uma equipe multidisciplinar.

Indicador 3- Governança Corporativa (Com relação à estrutura organizacional e práticas de governança corporativa):

Estágio 4: Além do exposto nos estágios anteriores, a alta administração (conselho e diretores) incorpora critérios de ordem socioambiental na definição e gestão do negócio e tem como norma ouvir, avaliar e considerar as preocupações, críticas e sugestões das partes interessadas em assuntos que as envolvam.

Indicador 4 - Relações com a Concorrência (Quanto às políticas de relacionamento com a concorrência ou com organizações de mesmo propósito, a empresa):

Estágio 4: Exerce posição de liderança em seu segmento nas discussões relacionadas à busca de padrões de concorrência cada vez mais elevados, considerando o combate à formação de trustes e cartéis, práticas desleais de comércio, fraudes em licitações e espionagem empresarial.

Indicador 5 - Diálogo e Engajamento das Partes Interessadas (Stakeholders) (Considerando seus impactos sobre distintos grupos da sociedade, a empresa):

Estágio 4: Por meio de ferramentas e políticas específicas, dialoga e envolve as partes interessadas de forma estruturada em reflexões prévias sobre suas atividades, processos e ações de forma a prever, minimizar ou eliminar as externalidades socioambientais negativas ocasionadas pela organização. Além disso, o processo de diálogo e engajamento é auditado por terceiros.

5.3. O processo de diálogo e engajamento das partes interessadas conta com indicadores de desempenho para monitoramento das relações.

5.4. A empresa tem política para que os indicadores/dados/informações advindos do processo de diálogo e engajamento das partes interessadas sejam, comparáveis, confiáveis, relevantes e compreensíveis por suas partes interessadas. 
Indicador 6 - Balanço Social (Com relação à elaboração de relatório sobre os aspectos econômicos, sociais e ambientais de suas atividades, a empresa):

Estágio 4: Elabora balanço social com envolvimento de partes interessadas externas, integrando as dimensões social, ambiental e econômica de suas atividades e incluindo resultados desfavoráveis e os respectivos desafios, com metas para o próximo período.

6.18. Quantas partes interessadas (público interno, fornecedores, comunidade, governo e sociedade etc.) estão envolvidas na elaboração do balanço social?

6.19. Quantas partes interessadas estão contempladas no demonstrativo de distribuição de riqueza?

Indicador 8 - Gestão Participativa (Quanto ao envolvimento dos empregados na gestão, a empresa):

Estágio 4: Representantes dos empregados participam ativamente dos comitês de gestão ou das decisões estratégicas e têm comunicação regular com os membros da governança.

Indicador 9 - Compromisso com o Futuro das Crianças (No tratamento da questão do combate ao trabalho infantil, a empresa):

9.1. discute com outras empresas ou apresenta propostas práticas para o combate ao trabalho infantil em seu setor (ou de maneira geral).

Indicador 18 - Comportamento nas Demissões (Para conduzir processos demissionais, a empresa):

18.3. busca estabelecer diálogo estruturado com instâncias do governo local, especialistas, ONGs e sindicatos para conhecer, entender, prever e reduzir o impacto de um possível fechamento de unidades de negócios ou plantas, ou da eventual necessidade de corte de pessoal.

18.5. diante da necessidade de redução de pessoal, prevê uma comunicação dirigida aos empregados remanescentes sobre as razões que balizaram a decisão tomada.

Indicador 19 - Preparação para a Aposentadoria (Visando preparar seus empregados para a aposentadoria, a empresa):

19.3. participa da elaboração de políticas públicas com foco em idosos.

19.4. participa ou apóia programas e campanhas públicas ou privadas de valorização dos idosos.

Indicador 20 - Compromisso com a Melhoria da Qualidade Ambiental (Para tratar com a devida relevância e responsabilidade os impactos ambientais resultantes de suas atividades, a empresa):

20.3. participa de comitês/conselhos locais ou regionais para discutir a questão ambiental com o governo e a comunidade.

Indicador 22 - Gerenciamento dos Impactos sobre o Meio Ambiente e do Ciclo de Vida de Produtos e Serviços (Considerando os impactos ambientais causados por seus processos e produtos ou serviços, a empresa):

22.5. discute com empregados, consumidores e clientes, fornecedores e a comunidade os impactos ambientais causados por seus produtos ou serviços. 
Indicador 26 - Trabalho Infantil na Cadeia Produtiva (Nas suas relações com fornecedores e parceiros, a empresa):

Estágio 4: Articula programas e atividades que visam erradicar o trabalho infantil de forma geral, em parceria com organizações da sociedade civil e/ ou do poder público.

Indicador 27 - Trabalho Forçado (ou Análogo ao Escravo) na Cadeia Produtiva (Nas suas relações com fornecedores e parceiros, a empresa):

Estágio 4: Articula programas e atividades que visam erradicar o trabalho forçado de forma geral, em parceria com organizações da sociedade civil e/ ou do poder público.

Indicador 29 - Política de Comunicação Comercial (Considerando a influência de sua política de comunicação comercial na criação de uma imagem de credibilidade e confiança, a empresa):

29.7. interage com seus fornecedores e distribuidores estimulando-os a adotar uma postura responsável em relação à comunicação voltada para o público infanto-juvenil.

Indicador 30 - Excelência no Atendimento (Quanto a seu compromisso com a qualidade dos serviços de atendimento ao consumidor/cliente, a empresa): Estágio 4: Promove melhoria contínua de seu atendimento, priorizando o diálogo e o engajamento das partes interessadas no processo.

Indicador 32 - Gerenciamento do Impacto da Empresa na Comunidade de Entorno (Considerando seus possíveis impactos na vida da comunidade (demanda sobre centros de saúde e lazer, creches, transporte público, tráfego de veículos etc.), a empresa:

Estágio 4: Além de possuir uma política formal de relacionamento com a comunidade, mantém comitês permanentes ou grupos de trabalho com a participação de lideranças locais para analisar suas atividades e monitorar seus impactos.

32.1. reconhece a comunidade em que está presente como parte interessada importante em seus processos decisórios.

32.2. possui políticas de relacionamento com a comunidade de entorno contempladas em seu código de conduta e/ou na declaração de valores. 32.3. participa ativamente da discussão de problemas comunitários e do encaminhamento de soluções.

Indicador 35 - Envolvimento com a Ação Social (Como forma de concretizar sua ação social, a empresa):

35.4. possui um conselho ou comitê misto, com membros de diferentes áreas da empresa ou do grupo empresarial, incluindo membros da sociedade credenciados para tratar da área temática em que atua.

Indicador 39 - Liderança e Influência Social (Buscando exercer sua cidadania por meio de associações e fóruns empresariais, a empresa):

Estágio 4: Tem membros de sua alta direção envolvidos na articulação, viabilização e fortalecimento de propostas de caráter socioambiental em diálogo com outras empresas, associações ou autoridades públicas visando sua adoção.

39.2. interage ativamente com instituições de ensino de todos os níveis a fim de elaborar propostas para melhorar a qualificação da mão-de-obra do setor em que atua. 
Observam-se alguns detalhes a serem esclarecidos nos excertos acima colocados. Primeiramente se faz menção ao "estágio 4" presente nas citações em muitos indicadores - e constantes em todos os indicadores presentes no formulário. Todos os indicadores tem estágios de implementação já descritos no formulário. Os primeiros estágios de todos os indicadores nada mais são do que o cumprimento de metas e obrigações legais - grosso modo, pode-se dizer que seria a função social -, o mínimo necessário para uma atuação dentro dos limites do ordenamento jurídico. Posteriormente os estágios seguintes vão traçando metas e valores mais elevados, que demonstram uma evolução ética, transparente e responsável de atuação até se chegar ao patamar máximo estipulado pelo Ethos como o mais próximo do ideal de social responsabilidade.

Todas as disposições contidas nos estágios 4, então, traçam uma espécie de “dever-ser”, dizendo como a empresa socialmente responsável deve agir em sua atividade para ser considerada socialmente responsável. Pode-se perceber que muitas dessas descrições falam de diálogo, engajamento, estreito relacionamento da empresa com seus stakeholders, independentemente do âmbito de atuação da empresa - seja na interface interna, externa ou com relação à sociedade.

Muitas vezes a interação com o stakeholder é condição sine qua non para caracterizar senão apenas do agir segundo uma função social, a exemplo da obrigação de as empresas respeitarem os direitos do consumidor, segundo determina a legislação pátria. Assim, a comunicação para saber como seu produto atinge dado público alvo, a disposição de uma ouvidoria para reclamações, a utilização do feedback do consumidor, enfim, essa interação básica nada mais se configura do que a mera obrigação legal a que a empresa deve se adstringir.

Verificar-se-á, outrossim, que as micro e pequenas empresas tem indicadores muito similares, mas em decorrência da abrangência de sua atividade, o questionário a que são submetidas é menos complexo, possui menos indicadores - são trinta e seis (36) ao todo - e, de modo geral, parece conter menos exigências ao enquadramento na gestão responsável socialmente.

Indicador 1 - Compromissos Éticos

A empresa possui documento escrito que esclarece quais são os comportamentos incentivados por ela no que se refere às relações pessoais e comerciais?

1.5. A empresa procura envolver suas partes interessadas (empregados, clientes, fornecedores, comunidade) na elaboração e revisão desse documento?

Indicador 26 - Gerenciamento do Impacto da Empresa na Comunidade de Entorno

A empresa se preocupa em estar sempre em contato com a comunidade de entorno, procurando minimizar os impactos negativos que suas atividades possam causar? 
26.2. convida moradores da região a participar de reuniões em que se abordem assuntos de interesse coletivo?

Indicador 32 - Benefícios para o Negócio

A empresa acredita que obteve benefícios para o negócio como resultado de sua atividade na comunidade de entorno?

32.6. A empresa faz um levantamento das necessidades locais antes de desenhar seus projetos na comunidade?

Indicador 33 - Participação e Influência Social

A empresa procura participar de organizações que integrem empresários (entidades empresariais, associações comerciais, fóruns regionais etc.)?

33.1. A empresa utiliza esse espaço para atualizar-se e discutir com outras empresas suas dificuldades, necessidades e formas de mobilização em busca de melhores condições tanto para os negócios quanto para a comunidade? ${ }^{12}$

Conforme mencionado, são menos exigências e os indicadores com itens destacados também se apresentam em menor número. $O$ realçado acima no formulário do Instituto Ethos em parceria com a SEBRAE segue idêntico raciocínio do exposto no formulário anteriormente colacionado. O diálogo é sempre importante para configurar a responsabilidade social. É neste requisito que todas as decisões a serem tomadas pela empresa serão legitimadas não somente pela coletividade no entorno de sua atividade, mas de todas as partes interessadas: sociedade, fornecedores, consumidores, empregados, acionistas, etc.

Cabe ainda fazer uma distinção entre a democracia na gestão empresarial e a democracia quanto ao relacionamento da empresa com seus parceiros interessados, no que tange à responsabilidade social. A primeira ocorre quando os empregados tornam-se parte ativa na gestão empresarial, promovendo ideias, participando de comitês executivos, tomando decisões nos três níveis empresariais - operacional, tático e estratégico. Já a segunda diz respeito à interação dialética entre a empresa e seus stakeholders - inclusive a sociedade envolvendo valores e interesses desse grupo, com o intuito de desenvolver ações direcionadas às expectativas que correspondam às necessidades dos mesmos.

Nesta esteira, vinculando a atuação das empresas que se pretendem socialmente responsáveis, existe uma norma nacional publicada em dezembro de 2004 pelo INMETRO $^{13}$, a ABNT/NBR 16001:2004, que estabelece minimamente alguns requisitos para um sistema de gestão da responsabilidade social, com alguns escopos que levem em consideração não unicamente as obrigações legais,

${ }^{12}$ http://www.ethos.org.br/docs/conceitos praticas/indicadores/download/

${ }^{13}$ Instituto Nacional de Metrologia, Normalização e Qualidade Industrial. 
porém também preceitos éticos de transparência e agir voltado à promoção da cidadania e desenvolvimento sustentável ${ }^{14}$.

Cumpre trazer à baila que, dentre os objetivos acima colocados e que são melhor pormenorizados na norma, deve haver uma definição da política de responsabilidade social com a consulta das partes interessadas e que na etapa de planejamento, a empresa deverá "estabelecer, implementar e manter objetivos e metas da Responsabilidade Social, com o envolvimento de funções e níveis relevantes dentro da organização e demais partes interessadas". (INMETRO, grifo nosso).

E, finalmente, não há como deixar de mencionar a famigerada ISO 26000. O Intercational Standard ISO 26000:2010 é

um guia em responsabilidade social, provê de maneira harmoniosa, um guia global relevante para setores privados e públicos de todos os tipos, baseado no consenso internacional entre representantes especialistas dos principais grupos de partes interessados, e fomenta as melhores práticas em responsabilidade social em todo o mundo. (ISO, grifo nosso). ${ }^{15}$

A ISO 26000 foi a norma mais aguardada sobre o assunto responsabilidade social, pois, de certa forma, acaba vinculando a atuação das empresas, que desejam a certificação de socialmente responsáveis para conseguir obter maior rentabilidade, lucro, permanência no mercado e ainda gozar da possibilidade de obter vantagens com o marketing social.

Atualmente os consumidores buscam cada vez mais produtos e serviços de empresas que têm essas características - ainda que apenas em decorrência do marketing social -, mesmo que mais caros. $\mathrm{O}$ denominado por alguns como "consumidor-cidadão" (FABIÃO, 2003) faz essas exigências, haja vista os atuais e crescentes problemas sociais, ambientais e, até mesmo, políticos. Uma empresa que demonstra sensibilidade para essas questões goza de maior confiança e, portanto, adquire a simpatia do público alvo.

${ }^{14}$ http://www.inmetro.gov.br/qualidade/responsabilidade social/iso26000.asp

15 "The International Standard ISO 26000:2010, Guidance on social responsibility, provides harmonized, globally relevant guidance for private and public sector organizations of all types based on international consensus among expert representatives of the main stakeholder groups, and so encourage the implementation of best practice in social responsibility worldwide."

http://www.iso.org/iso/iso catalogue/management and leadership standards/social responsibility/sr iso26000 overview.htm\#sr-1 
As instituições financeiras recorrem mais sistematicamente a listas de verificação de carácter social e ambiental para avaliarem os riscos da concessão de empréstimos a empresas ou de investimento nelas. Do mesmo modo, o reconhecimento de uma empresa como socialmente responsável - através, por exemplo, da sua inscrição num índice bolsista de valores éticos - reforça sua a cotação, acarretando, assim, vantagens financeiras $\operatorname{concretas}^{16}$. (COM, 2001, p. 8)

Não se pode desconsiderar o fato de que as empresas que se (auto)intitulam socialmente responsáveis desfrutam de maiores privilégios - em termos de preferência - frente ao consumidor-cidadão. Por isso a importância da supra mencionada ISO, uma vez que ao menos uma organização como a International Organization for Standardization, já formada por vários Estados e organizações internacionais, tenta balizar o tema e estabelecer algumas diretrizes, mesmo que em caráter de mera orientação, o fato de ser amplamente discutida internacionalmente tem um certo respaldo legítimo para vincular positivamente aquelas instituições que agem segundo tais diretrizes.

A ISO 26000 então é duplamente democrática porque sua publicação, no final de 2010, foi anterior e amplamente discutida em âmbito internacional - conquanto para sua existência houve “consenso internacional entre representantes especialistas dos principais grupos de partes interessados” -, conforme acima mencionado, e ainda traz em seu bojo para a aferição de responsabilidade social da empresa a necessidade de diálogo entre as partes interessadas.

Vai além, trazendo em seu âmago o trabalho que existirá pela frente no "desenvolvimento de um consenso internacional sobre o que responsabilidade social significa e as questões da responsabilidade social a que as organizações precisam se direcionar” ${ }^{\prime 17}$. (ISO) Isto quer significar que importante será o papel do debate acerca do tema, pois para se chegar a um consenso, deve haver

16 "Os índices sociais dos mercados de valores constituem indicadores úteis para demonstrar o impacto positivo da selecção social em matéria de resultados financeiros: desde o seu lançamento, em Maio de 1990, o Domini 400 Social Index superou o S\&P 500 por uma margem superior a $1 \%$ em termos de rendimento total anualizado e considerando um ajustamento de riscos, enquanto o Dow Jones Sustainable Index cresceu cerca de 180\% desde 1993, contra os 125\% do Dow Jones Global Index no mesmo período". (COM, 2001, p. 8).

17 "ISO 26000 both adds value to existing work on social responsibility (SR) and extends the understanding and implemention of SR by: Developing an international consensus on what SR means and the SR issues that organizations need to address". http://www.iso.org/iso/iso catalogue/management and leadership standards/social responsibility/sr iso26000 overview.htm\#sr-1 
amplo diálogo e discussão para haver, repete-se, a legitimidade das escolhas dos conceitos, normas, diretrizes.

Já se discutia sobre essas questões envolvendo responsabilidade social em documentos internacionais, como o Livro Verde: Promover um quadro europeu para a responsabilidade social das empresas, da Comissão das Comunidades Europeias em Bruxelas, 2001. Nesse documento, a começar pela síntese de seu conteúdo, já se pode perceber expressões como "pretendem, assim, dar um sinal às diversas partes interessadas com as quais interagem: trabalhadores, accionistas, consumidores, poderes públicos e ONG”, "conciliam os interesses de diversas partes", "no âmbito do diálogo social", demonstrando o que se tenciona trazer em todo trabalho, ou seja, a ideia de que para realização dos valores versados em objetivos e fundamentos do Estado Democrático de Direito, com o escopo de se alcançar o desenvolvimento sustentável, não se pode olvidar do pressuposto básico da democracia: o diálogo, consenso, discussão acerca das decisões, caminhos a serem tomados.

"Esta responsabilidade manifesta-se em relação aos trabalhadores e, mais genericamente, em relação a todas as partes interessadas afectadas pela empresa e que, por seu turno, podem influenciar os seus resultados." (COM, 2011, p. 4, grifo nosso).

Neste excerto do Livro Verde observa-se que as partes precisam participar e tornar os as decisões legítimas justamente porque são afetadas pela atividade empresarial e, como tal, tem o direito de opinar e discutir para que o resultado da atividade possa ser diferente, talvez, do que se observa na realidade, mas sempre segundo suas expectativas.

\section{CONCLUSÃO}

Comprovadamente via documentos internacionais e mesmo pela interpretação do ordenamento jurídico pátrio, verifica-se que o Estado Democrático de Direito não se efetiva apenas mediante atuação estatal. As empresas, os particulares, os cidadãos tem um papel em sua concretização, quando fazem valer os valores trazidos no Texto Constitucional, que nada mais são do que a razão de ser do próprio Estado.

Assim como o Estado possui o dever constitucional de perseguir e implementar esses valores, o mercado também é chamado à baila para cumprir sua parte, sob a fiscalização, controle e expectativas da sociedade. $\mathrm{O}$ afã de desenvolvimento sócio-econômico não é mais cabível somente ao Estado, nesta nova ótica.

Com isso, a responsabilidade social ganha papel de destaque e começa a ser um conceito pelo qual as empresas devem se balizar e, portanto, devem ter sua 
atuação democraticamente decidida. Essa democracia que envolve a atividade empresarial se faz perceber via diálogo, discussão, a fim de se chegar a consensos que legitimem a atuação da empresa, uma vez que toda a sociedade será afetada em razão desta.

\section{REFERÊNCIAS}

BERNARDO, Wesley de Oliveira Louzada. O princípio da dignidade humana e o novo Direito Civil: breves reflexões. Revista da Faculdade de Direito de Campos, ano 7, n. 8, p. 229-267, jun. 2006.

BOBBIO, Norberto. Estado, Governo, Sociedade: para uma teoria geral da política. Trad. Marco Aurélio Nogueira. 13. ed. São Paulo: Paz e Terra, 2007.

CARVALHO, William Eustaquio de. Caso Enron: breve análise da empresa em crise. 2004. Disponível em: 〈http://jus2.uol.com.br/doutrina/texto.asp?id=6045>. Acesso em: 29 mar. 2010.

COMISSÃO DAS COMUNIDADES EUROPEIAS (COM). Livro verde. Bruxelas, 18.07.2001. Disponível em: 〈http://www.europa.eu.int〉. Acesso em: 29 mar. 2010.

CORTINA, Adela. Ética Aplicada y democracia radical. 3. ed. Madri: Editorial Tecnos, 2001.

EMERIQUE, Lilian Márcia Balmant; GUERRA, Sidney. O princípio da dignidade da pessoa humana e o mínimo existencial. Revista da Faculdade de Direito de Campos, ano 7, n. 9, p. 379-397, dez. 2006.

FABIÃO, Maurício França. O negócio da ética: um estudo sobre o terceiro setor empresarial In: INSTITUO ETHOS. Responsabilidade social das empresas a contribuição das universidades. São Paulo: Peirópolis: Instituto Ethos, 2003. v. 2.

INSTITUTO NACIONAL DE METROLOGIA, NORMALIZAÇÃO E QUALIDADE INDUSTRIAL (INMETRO). Responsabilidade Social. Disponível em: <http://www. inmetro.gov.br/qualidade/responsabilidade social/iso26000.asp>. Acesso em: 07 ago. 2010.

INSTITUO ETHOS. Indicadores Ethos de Responsabilidade Social Empresarial. 2009a. Disponível em: $\leq$ http://www.ethos.org.br/ Uniethos/documents/IndicadoresEthos 2009 port.pdf $>$. Acesso em: 15 out. 2010.

. Indicadores Ethos-Sebrae de Responsabilidade Social Empresarial para micro e pequenas empresas. 2009b. Disponível em: <http://www.ethos.org.br/_Uniethos/ documents/IndicadoresEthos-Sebrae_2009_port.pdf>. Acesso em: 15 out. 2010. http:// www.ethos.org.br/docs/conceitos praticas/indicadores/download/

INTERNATIONAL ORGANIZATION FOR STANDARDIZATION - ISO. ISO 26000 - Social responsibility. Disponível em: http://www.iso.org/iso/iso catalogue/management and leadership standards/social responsibility/sr iso26000 overview.htm\#sr-1>. Acesso em: 20 set. 2010.

KANT, Immanuel. Fundamentação da Metafísica dos Costumes. Trad. Antônio Pinto de Carvalho. Rio de Janeiro: Companhia Editora Nacional, [19-].

LOCKE, John. Segundo tratado sobre o governo civil e outros escritos: ensaio sobre a 
origem, os limites e os fins verdadeiros do governo civil. Trad. Magda Lopes e Marisa Lobo da Costa. 4. ed. Bragança Paulista: Editora Universitária São Francisco; Petrópolis: Vozes, 2006.

PEREIRA, Juan Pablo Fernández. La seguridad humana. Barcelona: Editorial Ariel, 2006.

ROUSSEAU, Jean-Jacques. Do Contrato Social. Trad. Lourdes Santos Machado. São Paulo: Nova Cultural, 1999. v. 1. (Os Pensadores).

. Discurso sobre a origem e os fundamentos da desigualdade entre os homens. Trad. Lourdes Santos Machado. São Paulo: Nova Cultural (Os Pensadores), 1999. v. 2.

UNITED NATIONS. Disponível em: 〈http://www.un.org/>. Acesso em: 19 ago. 2008. VIEIRA, Evaldo. Direitos e Política Social. São Paulo: Cortez, 2004.

WHARTON SCHOOL. O que saiu errado na WorldCom? 2003. Disponível em: $\langle\underline{\text { http: } / /}$ www.wharton.universia.net/index.cfm? $\mathrm{fa}=$ viewfeature\&id $=448 \&$ language $=$ portuguese $>$. Acesso em: 29 mar. 2010.

Artigo recebido em 08/06/11 e aprovado para publicação 14/08/11 